\title{
General Amination Reactions for the Synthesis of Ynamides
}

\author{
Gwilherm Evano, ${ }^{\text {a }}$ Kévin Jouvin, ${ }^{\mathrm{b}}$ Alexis Coste ${ }^{\mathrm{b}}$ \\ ${ }^{a}$ Laboratoire de Chimie Organique, Service de Chimie et PhysicoChimie Organiques, Université Libre de Bruxelles, Avenue F. D. Roosevelt 50, \\ CP160/06, 1050 Brussels, Belgium \\ Fax+32(2)6502798; E-mail: gevano@ulb.ac.be \\ b Institut Lavoisier de Versailles, UMR CNRS 8180, Université de Versailles Saint-Quentin en Yvelines, 45, Avenue des Etats-Unis, \\ 78035 Versailles Cedex, France \\ Received: 30.10.2012; Accepted after revision: 22.11.2012
}

\begin{abstract}
The development of general syntheses of ynamides and related compounds based on various amination strategies are described in this short review. Reactions are classified according to the type of amination used and comparisons are made between all strategies to provide a comprehensive overview and to emphasize the advantages and limitations of each method.

1 Introduction: The ABC of Ynamides

2 Synthesis of Ynamides at the Dawn of the 21st Century: Elimination and Isomerization

3 Synthesis of Ynamides by Amination of/with Hypervalent Iodonium Salts

The Emergence of General Syntheses of Ynamides: CopperMediated Amination of Bromoalkynes, gem-Dibromoalkenes, and Alkynyl(triaryl)bismuthonium Tetrafluoroborates

5 Alternative Practical and Mild Syntheses of Ynamides: Copper-Catalyzed Oxidative Amination of Alkynes, Potassium Alkynyltrifluoroborates, and Propiolic Acids

6 'Click' Oxidative Amination of Copper Acetylides: A Practical Entry to Ynamides under Mild Conditions

7 Synthesis of Ynehydrazides by Electrophilic Amination of Lithium Acetylides with Diazodicarboxylates

8 Conclusions and Outlook: Ynamides Synthesis, Where Now?
\end{abstract}

Key words: ynamines, ynamides, $N$-alkynyl heterocycles, amination, copper catalysis, alkynes

\section{Introduction: The ABC of Ynamides}

While the first attempted preparation of nitrogen-substituted alkynes, ynamines, can be traced back to $1892,{ }^{1}$ these most valuable building blocks were only isolated in 1958. ${ }^{2}$ Serendipity, which is often cited as a key factor in making scientific discoveries, played a crucial role in this early breakthrough by Zaugg, Swett, and Stone at Abbott who reported an 'unusual reaction of propargyl bromide'. As mentioned in their publication, 'when an attempt to alkylate phenothiazine 1 with propargyl bromide failed using the customary conditions of sodamide in xylene, the procedure was changed to one using sodium hydride in dimethylformamide. Under these conditions, alkylation oc-

SYNTHESIS 2013, 45, 0017-0026

Advanced online publication: 03.12.2012

DOI: 10.1055/s-0032-1317880; Art ID: SS-2012-M0846-SR

(C) Georg Thieme Verlag Stuttgart · New York

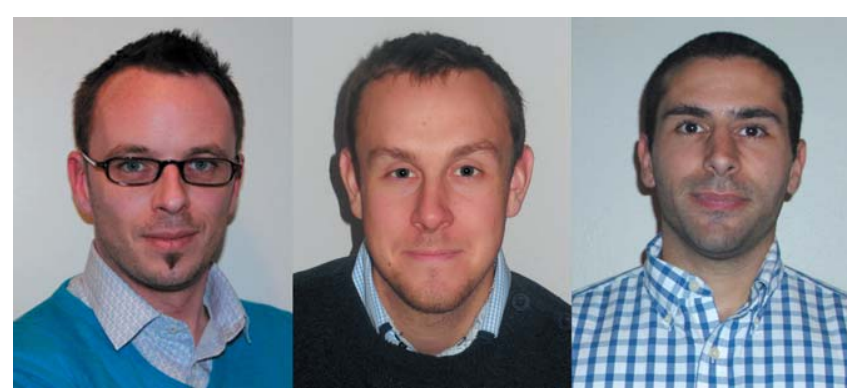

Gwilherm Evano (left) was born in 1977 and studied chemistry at the Ecole Normale Supérieure in Paris and received his Ph.D. from the Université Pierre et Marie Curie in 2002 under the supervision of Profs. François Couty and Claude Agami. After postdoctoral studies with Prof. James S. Panek at Boston University, he joined the CNRS as Chargé de Recherche at the University of Versailles in 2004. He then moved to the Université Libre de Bruxelles as Associate Professor in 2012. He was a recipient of the Award for vocation in Medicinal Society of the French Medicinal Society, the CNRS bronze medal, a Thieme Journal award, and the Acros Prize in organic chemistry of the French Chemical Society. He has coauthored 65 publications and 10 book chapters with research interests in developing copper-mediated transformations and the chemistry of heteroatom-substituted alkynes as well as the total synthesis of natural and/or biologically relevant products.

Kévin Jouvin (middle) was born in 1985 and studied chemistry at the University Joseph Fourier in Grenoble (France) where he did his undergraduate research with Dr. Demeunynck. He then joined the group of Gwilherm Evano in Versailles where his work focused on the development of new syntheses of heteroatom-substituted alkynes and on the development of copper-catalyzed transformations. He obtained his Ph.D. degree in October 2012 and joined the group of Prof. Alois Fürstner at the Max-Planck-Institut für Kohlenforschung as a postdoctoral fellow in November 2012.

Alexis Coste (right) was born in 1982 and studied chemistry at the Ecole Supérieure de Chimie Organique et Minérale. After undergraduate research with Profs. Lubin-Germain and Augé at the University of Cergy-Pontoise, he moved to the University of Versailles as a National Cancer Institute Fellow where his worked focused on the development of new copper-mediated transformations, including the synthesis of ynamides, and on natural product synthesis under the supervision of Gwilherm Evano. He obtained his Ph.D. degree in 2010 and since then he has been a postdoctoral research fellow at the Massachusetts Institute of Technology in the group of Prof. Mohammad Movassaghi.

curred to give a $70 \%$ yield of product which turned out to be $N$-(1-propyny1)phenothiazine 2 instead of the desired isomeric $N$-(2-propynyl)phenothiazine' (Scheme 1). Forty-eight grams of this product could be isolated and an ynamine was characterized for the first time. 


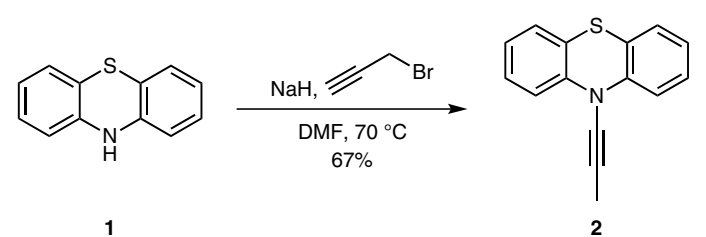

Scheme 1 The first synthesis of an ynamine (1958)

The synthetic potential of these nitrogen-substituted alkynes then became quickly apparent and their reactivity was extensively explored in the 1960s and 1970s, the great advantage of these building blocks being their high reactivity due to the polarizing effect of the nitrogen on the alkyne. ${ }^{3}$ This high reactivity was, however, also found to be a major limitation to the further extension of their use in organic synthesis. Ynamines are indeed readily hydrolyzed to the corresponding amides, which renders their preparation and handling difficult; their toxicity is an additional factor.

In sharp contrast, ynamides $\mathbf{3}$, compounds in which the donating ability of the nitrogen is diminished by the presence of an electron-withdrawing group on this atom, are less prone to hydrolysis and display an excellent balance between stability and reactivity. ${ }^{4}$ They can indeed, at least in most cases, be stored for years without degradation and are easily handled and purified using standard techniques. These compounds, which were actually introduced in 1972 by Viehe, ${ }^{5}$ include a whole range of nitrogen-substituted alkynes such as $N$-alkynyl-amides or $N$-alkynyllactams $4, N$-alkynyl-carbamates or $N$-alkynyl-oxazolidinones 5, $N$-alkynyl-sulfonamides or $N$-alkynyl-sultams $\mathbf{6}$, $\mathrm{N}$-alkynyl-ureas or $\mathrm{N}$-alkynyl-imidazolidinones 7, $\mathrm{N}$-alkynyl-imides (ynimides) 8, $\mathrm{N}$-phosphoryl-ynamines $\mathbf{9}$, and $N$-alkynyl-hydrazides 10 (Figure 1). Besides these compounds, other electron-deficient ynamines have recently emerged such as $\mathrm{N}$-alkynyl-conjugated heterocycles 11 and $N$-alkynyl-imines 12 (ynimines) that share with ynamides the same balance between stability and reactivity.

The stability of these ynamides provided by the presence of the electron-withdrawing group, which can also act as a chiral auxiliary or a directing group, make them ideal candidates for the design of new and original transformations. Indeed, their outstanding characteristics and the development of general methods for their synthesis have attracted the attention of an ever increasing number of research groups and an impressive array of new, efficient, selective, and remarkably elegant reactions have been developed from these building blocks over the past decade. A simple glance at the exponential evolution of the number of publications per year on the chemistry of ynamides is quite astounding and the 'ynamide boom' we men- tioned in our 2010 review is definitely happening (Figure 2). ${ }^{4 a, 6,7}$

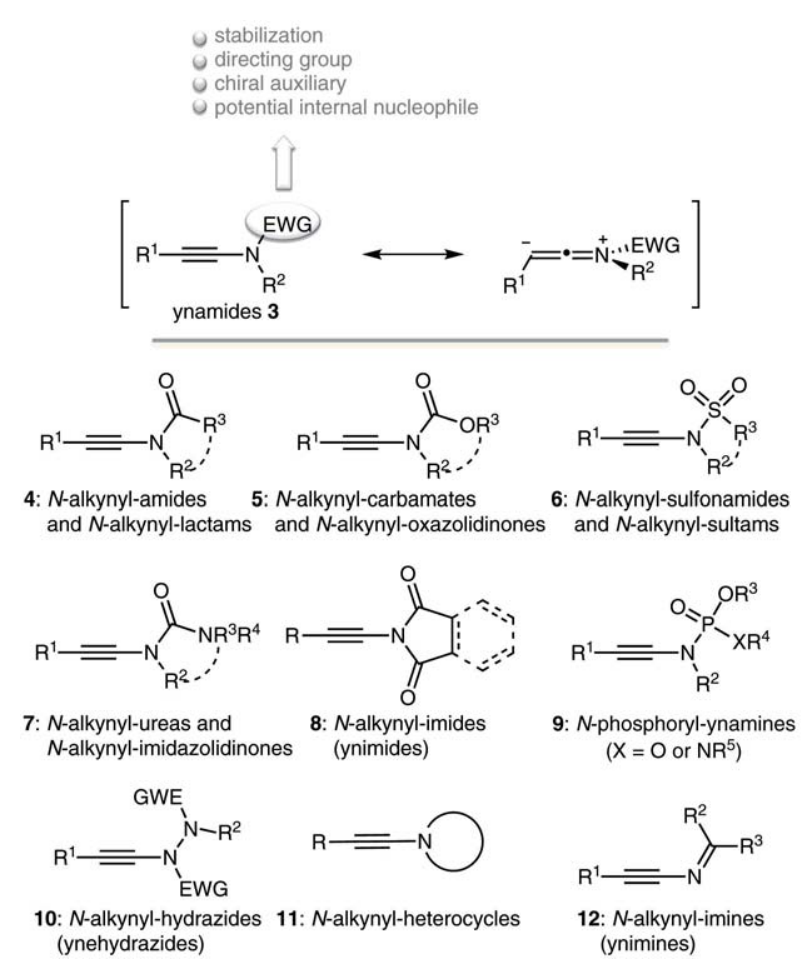

Figure 1 Ynamides and related nitrogen-substituted alkynes

The emergence of ynamides as a 'modern functional group for the new millennium', as nicely stated in Richard Hsung's review, ${ }^{4 b}$ is strongly related to the recent development of robust methods for their synthesis. These processes, based on various amination strategies, have replaced older procedures and most classes of ynamides are now readily available from various precursors, even on a multigram scale. These methods will be described in this short review, after a brief presentation of the more classical syntheses (section 2), and they have been classified according to the alkynylating agent used for the formation of the Csp-N bond (sections 3-7).

\section{Synthesis of Ynamides at the Dawn of the 21st Century: Elimination and Isomerization}

As mentioned in the introduction, the first synthesis of an ynamide was reported in 1972 by Viehe, some fourteen years after the first isolation of a nitrogen-substituted alkyne by Zaugg and co-workers. The synthesis of yne-urea 15 was based on the base-induced elimination of the corresponding $\alpha$-chloroenamide 14, itself obtained from reaction of $N$-methyl-2-phenylacetamide (13) with an excess of Viehe's salt followed by hydrolysis (Scheme 2). ${ }^{5}$ 


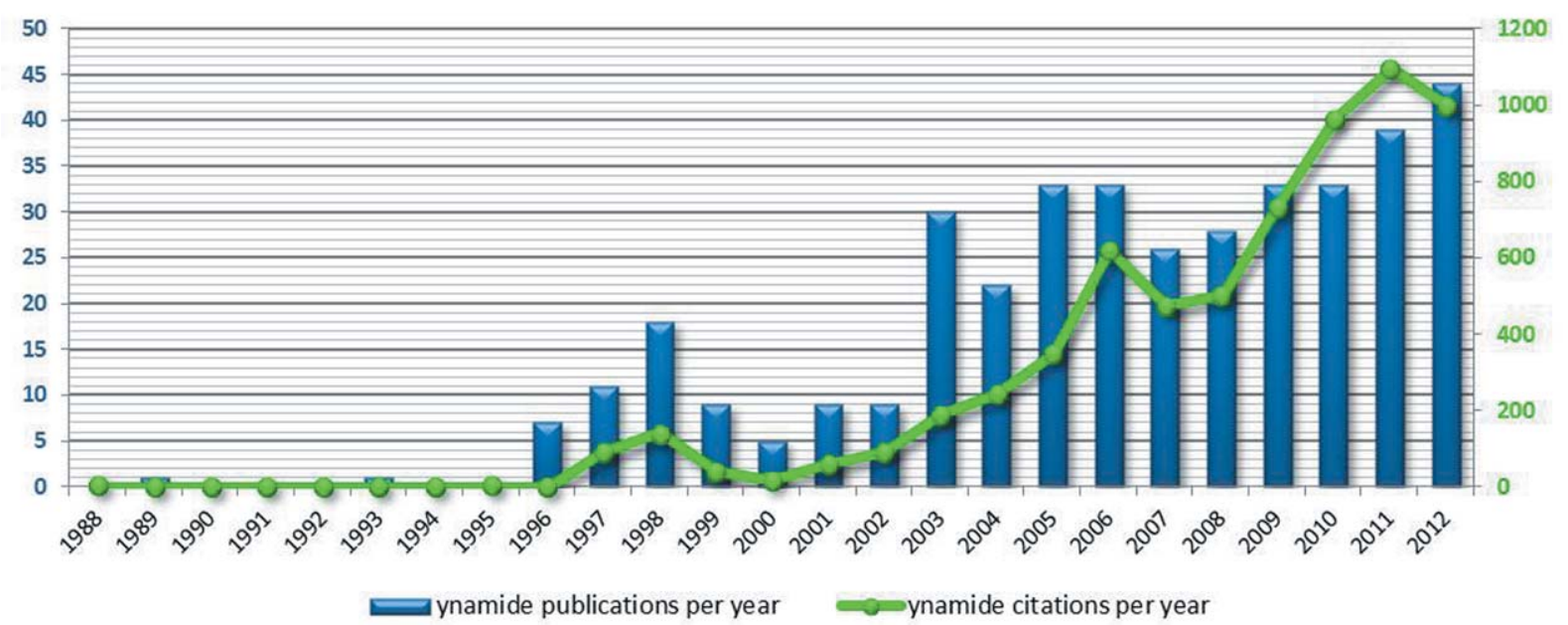

Figure 2 Ynamide publications and citations per year - the 'ynamide boom' (source: Web of Science ${ }^{\circledR}$, November 22 2012)

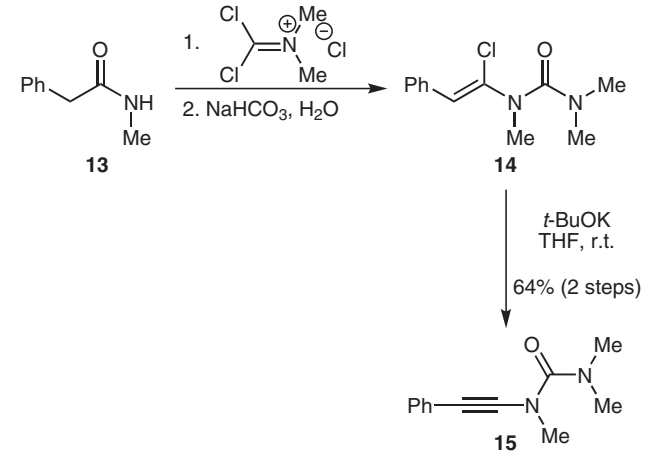

Scheme 2 The first synthesis of an ynamide (1972)

This result set the standard for the synthesis of ynamides for the next thirty years or so, their preparation by elimination from the corresponding halo-enamides being the method commonly used up to 2003. In 2001, the Hsung group extended this procedure to the use of $\beta$-bromoenamides 17 , compounds readily obtained by bromination of enamides 16 with bromine or $N$-bromosuccinimide. ${ }^{8}$ As in the Viehe's synthesis, potassium tert-butoxide was used for the elimination step, the major limitation being the absence of reactivity of the $E$-isomers of the starting $\beta$-bromoenamides 17 towards the key elimination (Scheme 3, eq 1). Besides $\alpha$-chloro- and $\beta$-bromoenamides [as well as $\beta$-(trifluoromethylsulfonyloxy)enamides $\left.{ }^{9}\right], \beta, \beta$-dichloroenamides 18, easily obtained by treatment of formamides with triphenylphosphine and tetrachloromethane, were also found to be suitable substrates for the preparation of ynamides based on an elimination strategy, this step being involved prior substitution of the second chloride by chloride/lithium exchange ${ }^{10}$ or after Suzuki-Miyaura crosscoupling ${ }^{11}$ (Scheme 3, eq 2 and 3). It should be noted that $\alpha, \beta$-dichloroenamides have also been used in related processes for the synthesis of $\mathrm{N}$-alkynyl-imidazoles. ${ }^{12}$
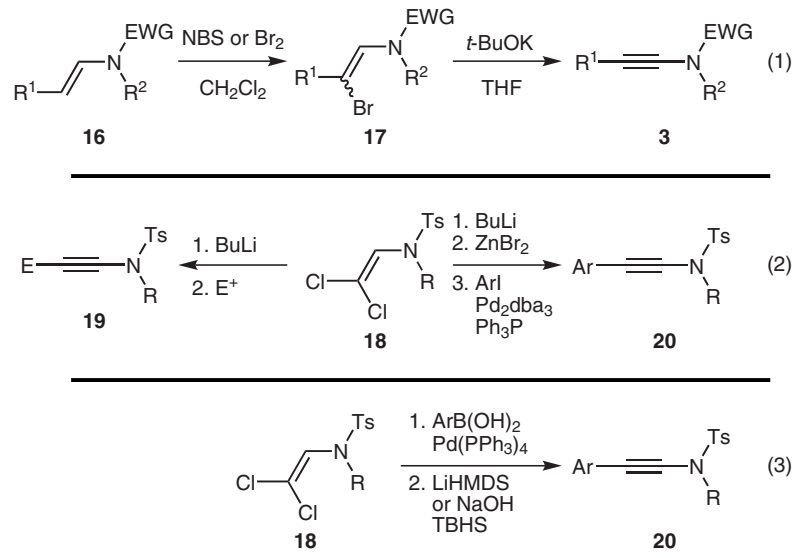

Scheme 3 Synthesis of ynamides based on elimination from haloenamides

Besides these routes to ynamides based on an elimination step from the corresponding halo-enamides that were developed on the basis of Viehe's original synthesis, the Zaugg procedure based on isomerization of propargylamines was also revisited. It was found to be a convenient route to nitrogen-substituted alkynes, at least before the emergence of more straightforward syntheses based on direct amination reactions. Indeed, the Hsung group extensively studied this transformation which was found to be rather efficient for the synthesis of yne-amides $\mathbf{2 2}$ (Scheme 4) ${ }^{13}$ the isomerization of other substrates such as $N$-propargyl-carbamates being less efficient. ${ }^{8}$

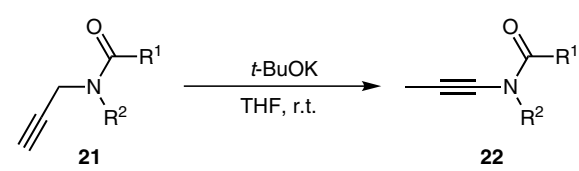

Scheme 4 Synthesis of ynamides based on isomerization of $N$-propargylamides 
These two main routes for the preparation of ynamides combined with the palladium- or copper-catalyzed functionalization of terminal ynamides ${ }^{10 b, e, 14}$ and the use of alkynyliodonium salts (vide infra) set the foundations of their chemistry. However, only a limited number of research groups were actually involved in this research area up to 2003, the preparation of the starting building blocks remaining a barrier to unleashing the full potential of ynamides. This situation has been resolved over the last ten years with the development of general, robust, and efficient methods for the preparation of these nitrogen-substituted alkynes which has had a dramatic impact on their chemistry, at least one paper on this topic is published every single week. While all syntheses of ynamides described so far rely on the formation of the triple bond, by elimination or isomerization, after formation of the $\mathrm{C}-\mathrm{N}$ bond, robust and more straightforward ynamide syntheses have been recently developed based on cross-coupling between an alkynylating agent and a nitrogen nucleophile or electrophile and these allow the formation of the $\mathrm{N}-\mathrm{C} \equiv \mathrm{C}$ motif in a single operation. An overview of these methods will be given in sections $3-7$, the methods have been classified according to the nature of both reaction partners, starting with the amination of acetylenic derivatives involving hypervalent iodonium salts.

Synthesis of Ynamides by Amination of/with Hypervalent Iodonium Salts

An interesting entry to ynamides, which also contributed to the revitalization of their chemistry, consists of the use of alkynyliodonium triflates, ${ }^{15}$ as originally described by Stang in 1994 for the preparation of push-pull ynamines. ${ }^{16}$ Upon reaction with lithium diphenylamide (23), alkynyl(phenyl)iodonium triflates 24 substituted with electron-withdrawing or trimethylsilyl groups were shown to smoothly transfer their alkynyl moiety, yielding stabilized ynamines 25 in moderate to good yields (Scheme 5, eq 1). Capitalizing on this result, this reaction was next extensively used for the preparation of a wide range of ynamides 3 with various efficiencies (Scheme 5, eq 2), notably by the groups of Witulski, Feldman, and Rainier, ${ }^{17}$ and extended to the preparation of several $\mathrm{N}$-alkynyl heterocycles. ${ }^{18}$ It should be noted that the use of a strong base such as BuLi or KHMDS is not strictly required with sulfonamides since the use of cesium carbonate was shown to be equally efficient in some cases. ${ }^{19}$

Although this reaction has proven to be rather useful, it requires in most cases the formation of the metalated N-nucleophile by reaction with a strong base such as BuLi or KHMDS and is limited by the poor availability of the starting iodonium salt, which can be substituted only by a proton or silyl, aromatic, or electron-withdrawing groups. In fact, the major advantages of this procedure are its utility for aminations involving acyclic secondary amides or other N-nucleophiles performing poorly in copper-mediated processes (such as acyclic secondary amides or bulky

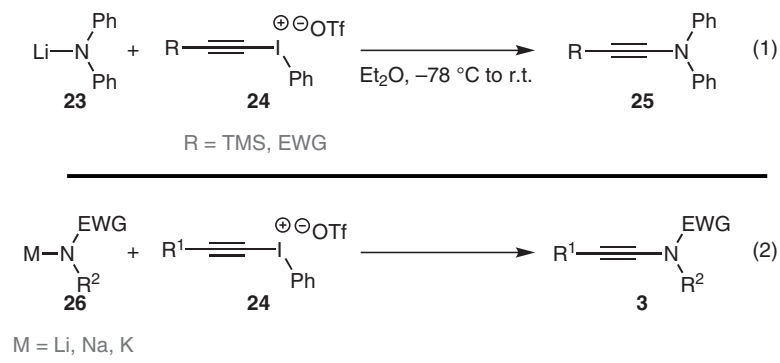

Scheme 5 Synthesis of push-pull ynamines and ynamides by amination of alkynyliodonium triflates with metalated N-nucleophiles

nucleophiles), the corresponding ynamides being rather difficult to prepare in good yields by other methods.

An especially interesting alternative was reported in 2012 by the Muñiz group. They developed an efficient metalfree direct amination of alkynes with bis(sulfonyl)aminederived aryliodonium acetates $\mathbf{2 7}$ (Scheme 6). These reagents, readily prepared by reaction of the corresponding bis(sulfonyl)amines with iodosobenzene diacetate, were shown to react smoothly with terminal aromatic alkynes 28 in 1,2-dichloroethane at $80{ }^{\circ} \mathrm{C}$ to give the corresponding aryl-substituted ynamides $\mathbf{2 9}$ in good yields and short reaction times. This reaction, therefore, represents a very useful alternative to the use of alkynyliodonium triflates, although the reactivity of other alkynes and other N-nucleophiles has not been reported. ${ }^{20}$

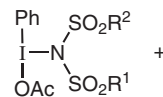

27

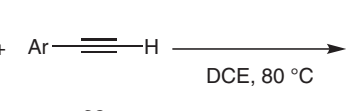

28

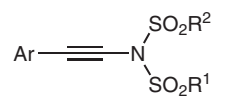

29
Scheme 6 Synthesis of ynamides by metal-free direct amination of alkynes with bis(sulfonyl)amine-derived aryliodonium acetates

The proposed mechanism for the formation of ynamides 3 from alkynyliodonium triflates $\mathbf{2 4}$ is shown in Scheme 7. It would first involve nucleophilic addition of the metalated $\mathrm{N}$-nucleophile $\mathbf{2 6} \beta$ to the iodine in $\mathbf{2 4}$ followed by a 1,2 -shift from the resulting vinylcarbene $\mathbf{3 0}$ to form ynamide 3. The intermediacy of an alkynyliodonium salt was proposed to account for the formation of ynamides from bis(sulfonyl)amine-derived aryliodonium acetates 27, the former being formed by dissociation of the latter followed by reversible coordination of the electrophilic iodine(III) to the alkyne yielding $\mathbf{3 1}$ and loss of acetic acid by internal deprotonation of the acidified $\mathrm{C}-\mathrm{H}$ bond in $\mathbf{3 1}$.

In addition to these routes, which provide interesting entries to ynamides especially with poor nucleophiles in the first case and for the preparation of aryl-substituted $N, N$ bis(sulfonyl)ynamines in the second, major advances in the chemistry of ynamides have been made since 2003 by the use of copper-mediated cross-coupling reactions. General and robust procedures have been developed using copper catalysis for the amination of an impressive range of acetylenic reagents or synthetic equivalents. These syn- 


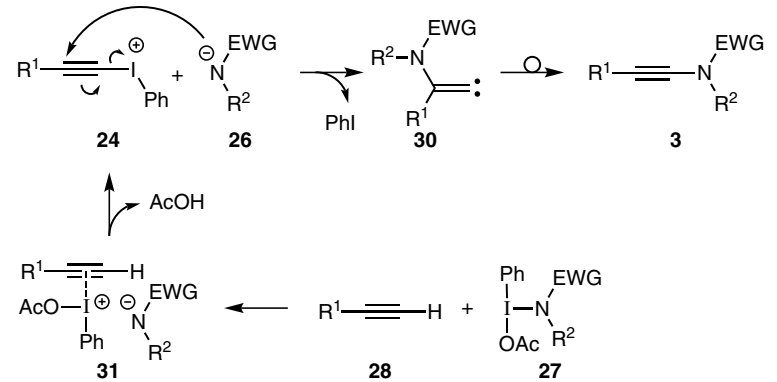

Scheme 7 Proposed mechanism for the formation of ynamides from alkynyliodonium triflates and bis(sulfonyl)amine-derived aryliodonium acetates

theses and their scope and limitations will be discussed in sections 4 and 5 of this short review.

\section{The Emergence of General Syntheses of Ynamides: Copper-Catalyzed Amination of Bromoalkynes, gem-Dibromoalkenes, and Alkynyl(triaryl)bismuthonium Tetrafluo- roborates}

As already mentioned, the renaissance of coppercatalysis $^{21}$ and the remarkable work from the Buchwald group for the development of mild Ullmann-Goldbergtype cross-coupling reactions ${ }^{22}$ had a deep impact on the chemistry of ynamides. Indeed, inspired by early results from the Buchwald group, Hsung and co-workers reported in early 2003 a straightforward method for their preparation. Using a combination of copper(I) cyanide, $N, N^{\prime}$ dimethylethylenediamine, and potassium phosphate in refluxing toluene, they demonstrated that alkynyl bromides 32 could be readily aminated with oxazolidinones, cyclic secondary amides, and carbamates 33 to give the corresponding ynamides 3 in moderate to good yields (Scheme 8 , eq 1). ${ }^{23}$ While these results represented a significant breakthrough, the substrate scope was, however, quite narrow, low yields being obtained with most amides, and the reaction being inefficient with sulfonamides. A related procedure was published almost simultaneously by the Danheiser group who reported that the amination of bromoalkynes $\mathbf{3 2}$ could be performed at room temperature provided that the $\mathrm{N}$-nucleophiles were deprotonated with KHMDS prior to cross coupling and that stoichiometric amounts of copper(I) iodide in pyridine were used (Scheme 8, eq 2). ${ }^{24}$ Using these conditions, carbamates, oxazolidinones, imidazolidinones, and sulfonamides were successfully transformed into the corresponding ynamides $\mathbf{3}$ in good yields.

A more general procedure, probably one of the best routes to ynamides to date, was next published in 2004 by the Hsung group who reoptimized its catalytic system in order to broaden the scope of their amination. The combination of copper(II) sulfate pentahydrate and 1,10-phenanthroline was found to be especially efficient for the amination

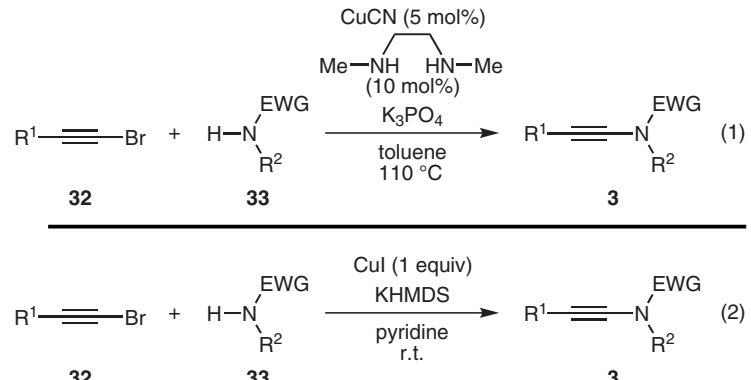

Scheme 8 Synthesis of ynamides by copper-mediated amination of alkynyl bromides: the first developments. Hsung's 1st generation (eq 1) and Danheiser's procedure (eq 2).

of bromoalkynes 32 with most classes of nitrogen nucleophile 33 (carbamates, oxazolidinones, lactams, acyclic secondary amides, imidazolidinones, and sulfonamides) with remarkable efficiency (Scheme 9). ${ }^{25}$ This procedure, which was also performed intramolecularly, was later on extended to other nitrogen nucleophiles such as bulky carbamates, ${ }^{26}$ phosphoramidates, ${ }^{27}$ diethylamine (although the intermediate ynamines could not be isolated and dimerized to the corresponding naphthalene-1,3-diamine $)^{28}$ and various $\pi$-excessive nitrogen heterocycles (imidazoles, benzimidazoles, pyrazoles, indazoles) ${ }^{29}$ using slight modifications of Hsung's system. As an important note, the origin of potassium phosphate is crucial for the success of the reaction, the presence of hydrates providing lower yields of ynamides. ${ }^{30}$ It should also be mentioned that iron(III) chloride was also reported to be an efficient catalyst for the exact same transformation, ${ }^{31}$ although no control experiments to determine the role of copper impurities in iron salts, which were recently shown to be crucial in related processes, ${ }^{32}$ were performed.

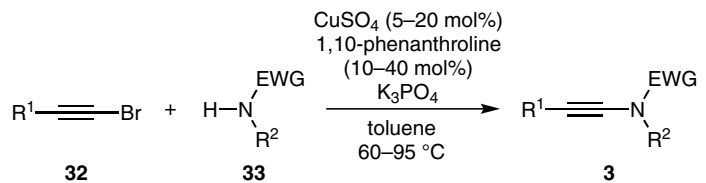

Scheme 9 Synthesis of ynamides by copper-catalyzed amination of alkynyl bromides: Hsung's 2nd generation procedure

The use of the direct amination of bromoalkynes with Nnucleophiles provided the sought-after general and straightforward entry to ynamides. This procedure is, however, not universal, the synthesis of electron-rich aromatic bromoalkynes being problematic in some cases and the preparation of alkyl-substituted ones being quite painful due to their volatility and lachrymatory properties. Alternative reagents were, therefore, needed and we introduced gem-dibromoalkenes $34^{33}$ as cross-coupling partners in 2009. These compounds, which are readily prepared by the Ramirez olefination or the more practical Lautens modification from the corresponding aldehydes, ${ }^{34}$ were shown to be efficient reagents for the synthesis of a wide range of ynamides from sulfonamides, oxazolidinones, carbamates, and lactams (Scheme 10). ${ }^{35}$ 
The choice of the base and solvent turned out to be crucial for this transformation to avoid the competitive formation of diynes, ${ }^{36}$ ketene $N, N$-acetals, ${ }^{37}$ or $\alpha$-bromoenamides. ${ }^{35 c}$ The combination of cesium carbonate and dioxane or DMF was found to be optimal and provided the desired ynamides in good yields, even on complex substrates. We next extended this procedure to benzimidazoles and indazoles, ${ }^{38}$ a reaction where TMEDA instead of the $N, N^{\prime}$-dimethylethylenediamine ligand we used in our original procedure was found to be quite efficient ${ }^{39}$ and which could be also performed with the preformed complex $\left[\mathrm{Cu}(\right.$ phen $\left.) \mathrm{PPh}_{3} \mathrm{Br}\right]$ with improved efficiency. ${ }^{40}$ As a note, 1,2-dibromostyrenes were also shown to be suitable reaction partners for the cross coupling with sulfonamides, which might provide an alternative entry to $\mathrm{N}$-sulfonylynamines, although the synthesis of these reagents is less trivial than the preparation of the corresponding gemdibromides. ${ }^{41}$

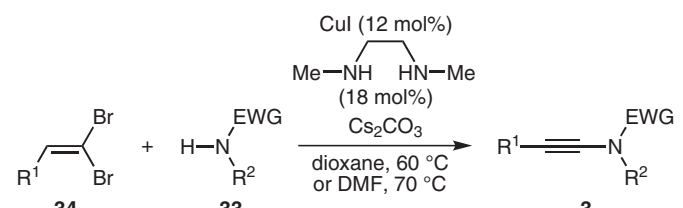

Scheme 10 Synthesis of ynamides by copper-catalyzed amination of gem-dibromoalkenes

Bromoalkynes and gem-dibromoalkenes have been extensively used for the preparation of ynamides, hundreds of these building blocks having been made by amination of these reagents. In addition to these syntheses, the quest for alternative reagents that would be commercially available and/or whose amination could proceed under milder conditions (ideally at room temperature and without a base) resulted in the development of alternative routes to ynamides. In this context, a remarkable synthesis of $\mathrm{N}$-alkynyl-imides (ynimides 8), synthetic equivalents of highly labile primary ynamines, was reported in 2011 based on the amidation of alkynyl(triaryl)bismuthonium tetrafluoroborates $35 .^{42}$ These reagents, which are prepared by reaction of the corresponding trifluoroborates with triaryldifluorobismuth, boron trifluoride-diethyl ether complex, and sodium tetrafluoroborate, were shown to react readily with five-membered-ring imides $\mathbf{3 6}$ in the presence of a catalytic amount of copper(I) bromide and triethylamine in dichloromethane at $-40{ }^{\circ} \mathrm{C}$. The corresponding ynimides $\mathbf{8}$ were obtained in moderate to good yields along with products resulting from competitive transfer of one aryl group of the starting bismuthonium salt 35 (Scheme 11). While these reagents require several steps for their preparation, which somehow reduces their synthetic use, they, however, offer the only general entry to ynimides available to date.

Other efficient strategies that provide mild and/or practical entries to ynamides based on copper-catalyzed oxidative cross-coupling reactions ${ }^{43}$ have been reported recently: an overview is given in section 5 .

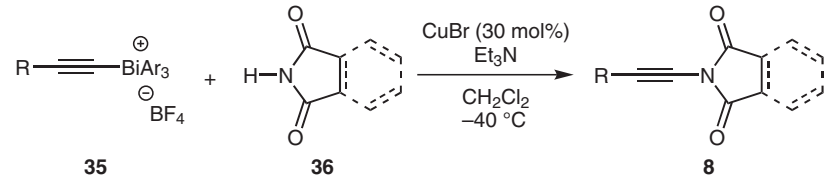

Scheme 11 Synthesis of ynimides by copper-catalyzed amination of alkynyl(triaryl)bismuthonium tetrafluoroborates

\section{Alternative Practical and Mild Syntheses of Ynamides: Copper-Catalyzed Oxidative Amination of Alkynes, Potassium Alkynyltri- fluoroborates, and Propiolic Acids}

An attractive synthesis of ynamides based on the direct aerobic amination of alkynes 37 was reported by the Stahl group in 2008. Capitalizing on two early reports from Peterson $^{44}$ and Balsamo and Domiano, ${ }^{45}$ they developed an efficient catalytic system based on copper(II) chloride in combination with pyridine, sodium carbonate, and oxygen as the terminal oxidant in toluene at $70{ }^{\circ} \mathrm{C}$ to promote the direct cross-coupling between a wide range of terminal alkynes 37 and oxazolidinones, lactams, imidazolidinones, sulfonamides, and indoles 33 (Scheme 12). ${ }^{46}$ The corresponding ynamides $\mathbf{3}$ were obtained in good yields from commercially available precursors, the sole limitation of this process being the requirement for five equivalents of the $\mathrm{N}$-nucleophile and the slow addition of the alkyne to minimize its competitive Glaser-Hay oxidative dimerization. This reaction was later on extended to the use of a recyclable copper carboxylate metal-organic framework catalyst. ${ }^{47}$ In addition, the development of heterogeneous processes based on the replacement of the soluble copper(II) chloride by stoichiometric copper(II) oxide (in combination with potassium chloride and 4-phenylpyridine $)^{48}$ or copper(II) hydroxide (in the presence of potassium carbonate, cesium carbonate, or cesium hydroxide $^{49}$ allows overcoming the requirement for the slow addition of the alkyne and a reduction in the amount of the N-nucleophile to two or three equivalents. The scope of the oxidative amination was, however, not fully examined in the first case since only aromatic alkynes were used in the study.

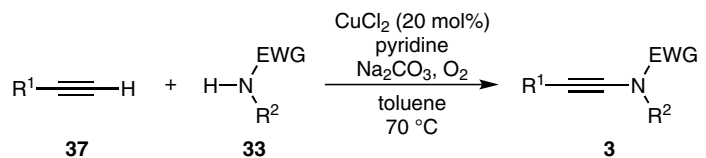

Scheme 12 Synthesis of ynamides by copper-catalyzed oxidative amination of terminal alkynes

In an effort to develop an efficient entry to ynimines, interesting variants of ynamines whose use remains rather limited, mostly due to the difficulties associated with their preparation, we screened various reagents and conditions 
for the direct alkynylation of imines. We eventually found that the Stahl procedure was the only efficient one, a wide range of terminal alkynes 37 being readily aminated with diarylimines 38 to give the corresponding ynimines 39 in fair to good yields (Scheme 13). This provided the first general synthesis of ynimines, although restricted to the use of diarylimines as starting materials, the replacement of one aryl group by an alkyl chain resulting in extensive degradation of both the starting imine and the resulting ynimine. ${ }^{50}$

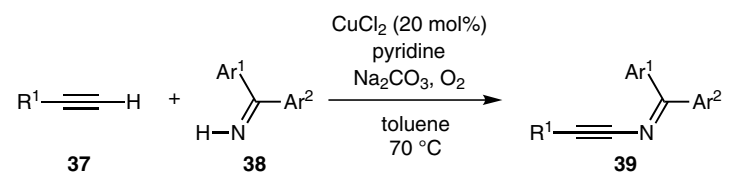

Scheme 13 Synthesis of ynimines by copper-catalyzed oxidative amination of terminal alkynes with diarylimines

While the direct amination of alkynes provided a practical entry to ynamides from commercially available starting materials, this procedure, as those previously described, still required the use of a base and/or elevated temperature, which can be a strong limitation for the preparation of sensitive ynamides, a problem we faced in various projects. A logical evolution of the ynamide synthesis that might allow these limitations to be circumvented would be to extend the Chan-Lam-Evans coupling involving aryl- or vinylboronic acids, ${ }^{51}$ which typically proceed under mild conditions, to their acetylenic analogues. If we were at first surprised to note that alkynylboronic acids had not been reported, ${ }^{52}$ we quickly realized why, since all attempts to isolate these reagents resulted in extensive degradation or, in the best case, protodeborylation. We therefore decided to switch to potassium alkynyltrifluoroborates $\mathbf{4 0},{ }^{53}$ perfectly stable crystalline compounds that are readily prepared from the corresponding alkynes, and demonstrated that they were readily cross-coupled to a wide range of $\mathrm{N}$-nucleophiles 33 including oxazolidinones, imidazolidinones, and sulfonamides (lactams gave lower yields) in good yields (Scheme 14). ${ }^{54}$ The reaction proceeded smoothly at room temperature and in the absence of base using a combination of copper(II) chloride dihydrate and 1,2-dimethylimidazole together with $4 \AA$ molecular sieves and oxygen. The solvent was found to be a key parameter in this reaction and the use of dichloromethane allowed the homocoupling of the starting potassium alkynyltrifluoroborates $\mathbf{4 0}$ to be suppressed by diminishing their solubility $\left(5 \times 10^{-3} \mathrm{~mol} \cdot \mathrm{L}^{-1}\right.$ in this solvent). This procedure provided the first base-free, room temperature synthesis of ynamides, which might be especially attractive for the preparation of sensitive ynamides or for substrates possessing potentially reactive functional groups such as halides or unprotected alcohols.

It was next demonstrated that propiolic acids $\mathbf{4 1}$ could also be used for the synthesis of oxazolidinone-, imidazolidinone-, lactam-, sulfonamide- and indole-derived yn-

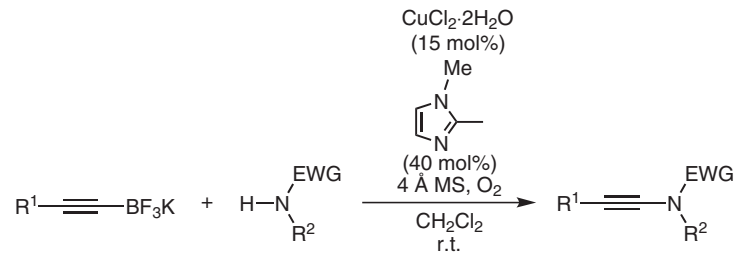

40

33

Scheme 14 Room temperature, base-free synthesis of ynamides by copper-catalyzed oxidative amination of potassium alkynyltrifluoroborates

amides 3 by copper(II) chloride catalyzed decarboxylative cross-coupling under ligand-free conditions (Scheme 15). ${ }^{55}$ The resulting ynamides were obtained in moderate to good yields and this reaction, which requires protracted heating at $100{ }^{\circ} \mathrm{C}$ for the decarboxylation step, represents an alternative entry to ynamides provided that the propiolic acids required are readily available.

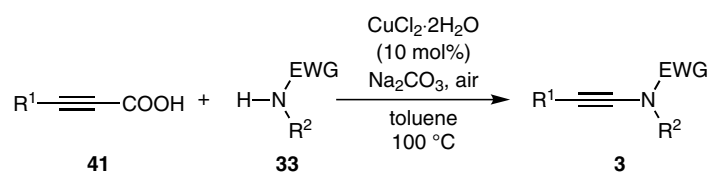

Scheme 15 Synthesis of ynamides by copper-mediated decarboxylative and oxidative amination of propiolic acids

As shown by all of the results described so far in this article, a wide range of procedures and reagents are available for the preparation of ynamides possessing various substitution patterns. These developments are clearly at the origin of the extraordinary development of the chemistry of these building blocks over the last years, most classes of ynamides being readily prepared by carefully choosing the appropriate procedure.

In continuation of our research program on the chemistry of ynamides, we needed to prepare, for various projects, large quantities of ynamides. If they can be successfully synthesized on a multigram scale using the syntheses we developed with gem-dibromoalkenes and potassium alkynyltrifluoroborates or Hsung's 2nd generation or Stahl's procedures, we struggled with some substrates and felt at some point that an even more practical synthesis would be helpful. This led us to develop a 'click' aerobic amination of copper acetylides which will be described in section 6 .

\section{6 'Click' Oxidative Amination of Copper
Acetylides: A Practical Entry to Ynamides
under Mild Conditions}

As a gross simplification, and although there is still no evidence on the mechanisms of these reactions, most copper-catalyzed cross-coupling discussed in sections 4 and 5 are thought to proceed via an alkynylamidocopper(III) complex. A fast reductive elimination would account for 
the formation of ynamides from this intermediate, which could be generated, in a rate-determining step, either by oxidative addition (section 4) or by transmetalation/oxidation (section 5). With this basic picture in mind, we envisioned the possibility of generating such intermediates by oxidation of the corresponding copper acetylides $\mathbf{4 2}$ in the presence of $\mathrm{N}$-nucleophiles, which might allow the development of a practical synthesis of ynamides under mild conditions. ${ }^{56}$ These rock-stable, non-reactive alkynylcopper reagents are easily prepared by simple reaction of the corresponding terminal alkynes with copper iodide either in a mixture of aqueous ammonia and ethanol or in DMF in the presence of potassium carbonate followed by filtration. As expected, they were found to smoothly react with oxazolidinones and lactams under an atmosphere of oxygen by simple activation with one equivalent of TMEDA (Scheme 16, eq 1) at room temperature. ${ }^{57}$ In terms of scope this procedure is restricted to unhindered lactams and oxazolidinones, which must be used in excess. The major advantage, however, lies in its operational simplicity. Indeed, this self-indicating reaction (upon completion, the reaction mixture turns from a yellow heterogeneous suspension to a blue solution that can be loaded directly on to a plug of silica gel) is readily performed in most common solvents ( $\mathrm{MeCN}, \mathrm{CH}_{2} \mathrm{Cl}_{2}$, toluene, THF, DMF, EtOH, THF $-\mathrm{H}_{2} \mathrm{O}$, or neat), without specific precautions, from copper acetylides $\mathbf{4 2}$ that are easily prepared on a multigram scale without purification. This procedure might not be the most general in terms of scope, but is certainly among the most practical and can conveniently be applied to the preparation of complex ynamides or for large-scale ynamide synthesis. This reaction was next extended to the oxidative alkynylation of imines 43 , in order to overcome the limitations of our first generation procedure (Scheme 13). 1,2-Dimethylimidazole was found to be the best promoter in this case and a wide range of copper acetylides were smoothly transformed to the corresponding ynimines 44 in good yields (Scheme 16, eq 2). ${ }^{58}$
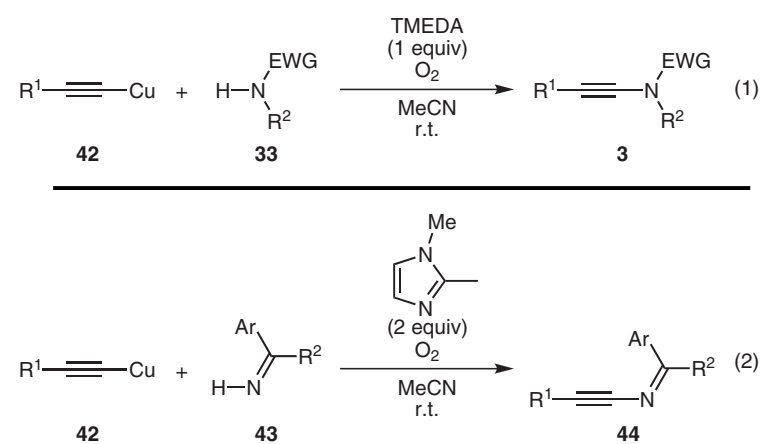

Scheme 16 Synthesis of ynamides and ynimines by oxidative amination of copper acetylides

\section{$7 \quad$ Synthesis of Ynehydrazides by Electrophilic Amination of Lithium Acetylides with Diazodicarboxylates}

Finally, an amination procedure that was found to be especially convenient for the synthesis of ynehydrazides should be mentioned. While this virtually unknown class of ynamides, which clearly offers various possibilities in organic synthesis, could not be obtained in decent yields by copper-promoted amination of bromoalkynes with protected hydrazides, a reversal of the polarities of the reagents was found to be more successful. Indeed, the Batey group prepared a variety of ynehydrazides $\mathbf{4 7}$ in good yields by addition of lithium acetylides $\mathbf{4 5}$ to sterically hindered diazodicarboxylates such as di-tert-butyl azodicarboxylate $\left(46, \mathrm{R}^{2}=t\right.$ - $\left.\mathrm{Bu}\right)$ and diisopropyl azodicarboxylate $\left(\mathbf{4 6}, \mathrm{R}^{2}=i\right.$-Pr $)($ Scheme 17$) .{ }^{59}$

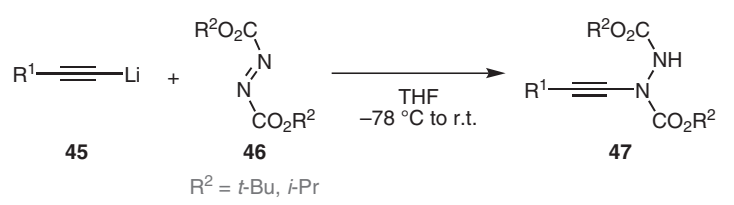

Scheme 17 Synthesis of ynehydrazides by amination of lithium acetylides with diazodicarboxylates

\section{Conclusions and Outlook: Ynamides Synthesis, Where Now?}

Continuous progress has been made in the synthesis of ynamides by formation of the Csp- $\mathrm{N}$ bond by various amination strategies over the last ten years. Most classes of ynamides and related nitrogen-substituted alkynes are now available and the preparation of multigram quantities of these building blocks is no longer problematic. The development of these syntheses clearly contributed to the emergence of ynamides in organic synthesis, remarkable reports being published on a weekly basis showcasing their unique reactivity. There is no doubt that this trend will continue for years to come, the exceptional reactivity of ynamides being far from fully exploited and their use in natural product synthesis and in medicinal chemistry clearly being under-utilized.

Although these tremendous advances have considerably simplified the synthesis of ynamides, this is, however, not a problem solved. Indeed, the preparation of some classes of ynamides remains problematic, amination procedures involving substrates such as acyclic secondary amides or ureas being either highly substrate-dependent or completely inefficient, which strongly limits their development. New classes of ynamides such as ynehydrazides, ynimides, $N$-phosphoryl-ynimines, or ynimines have also recently appeared and further developments in the chemistry of ynamides will also involve the development of new members within this family. 
In short, ynamides will definitely continue to occupy an important role in organic synthesis and we hope this short review will motivate other research groups to explore the reactivity of these unique building blocks. There is clearly exciting chemistry to be discovered with ynamides: try it, you'll like it!

\section{Acknowledgment}

The authors thank the CNRS, the University of Versailles, the University of Brussels and the ANR (projects DYNAMITE ANR2010-BLAN-704 and VINFLUSUP ANR-11-JS07-003-01) for financial support. K.J. and A.C. respectively acknowledge the Ministère de la Recherche and the National Cancer Institute for graduate fellowships.

\section{References}

(1) (a) Bode, J. Justus Liebigs Ann. Chem. 1892, 267, 268. For a correction, see: (b) Klages, F.; Drerup, E. Justus Liebigs Ann. Chem. 1941, 547, 65.

(2) Zaugg, H. E.; Swett, L. R.; Stone, G. R. J. Org. Chem. 1958, $23,1389$.

(3) For general references on the chemistry of ynamines, see: (a) Ficini, J. Tetrahedron 1976, 32, 1449. (b) Witulski, B.; Alayrac, C. In Science of Synthesis: Houben-Weyl Methods of Molecular Transformations; Vol. 24; de Meijere, A., Ed.; Thieme: Stuttgart, 2005, 1007.

(4) For recent reviews on the chemistry of ynamides, see: (a) Evano, G.; Coste, A.; Jouvin, K. Angew. Chem. Int. Ed. 2010, 49, 2840. (b) DeKorver, K. A.; Li, H.; Lohse, A. G.; Hayashi, R.; Lu, Z.; Zhang, Y.; Hsung, R. P. Chem. Rev. 2010, 110, 5064.

(5) Janousek, Z.; Collard, J.; Viehe, H. G. Angew. Chem. Int. Ed. 1972, 11, 917.

(6) For selected key references on the development of new reactions from ynamides over the last five years, see: (a) Das, J. P.; Chechik, H.; Marek, I. Nat. Chem. 2009, 1, 128. (b) Gourdet, B.; Lam, H. W. J. Am. Chem. Soc. 2009, 131, 3802. (c) Li, H.; Hsung, R. P.; DeKorver, K. A.; Wei, Y. Org. Lett. 2010, 12, 3780. (d) Valenta, P.; Carroll, P. J.; Walsh, P. J. J. Am. Chem. Soc. 2010, 132, 14179. (e) Davies, P. W.; Cremonesi, A.; Dumitrescu, L. Angew. Chem. Int. Ed. 2011, 50, 8931. (f) Kramer, S.; Odabachian, Y.; Overgaard, J.; Rottlander, M.; Gagosz, F.; Skrydstrup, T. Angew. Chem. Int. Ed. 2011, 50, 5090. (g) Schotes, C.; Mezzetti, A. Angew. Chem. Int. Ed. 2011, 50, 3072. (h) Pizzetti, M.; Russo, A.; Petricci, E. Chem.-Eur. J. 2011, 17, 4523. (i) Shindoh, N.; Kitaura, K.; Takemoto, Y.; Takasu, K. J. Am. Chem. Soc. 2011, 133, 8470. (j) Mukherjee, A.; Dateer, R. B.; Chaudhuri, R.; Bhunia, S.; Karad, S. N.; Liu, R.-S. J. Am. Chem. Soc. 2011, 133, 15372. (k) Greenaway, R. L.; Campbell, C. D.; Holton, O. T.; Russell, C. A.; Anderson, E. A. Chem.-Eur. J. 2011, 17, 14366. (1) Dateer, R. B.; Shaibu, B. S.; Liu, R.-S. Angew. Chem. Int. Ed. 2012, 51, 113. (m) Compain, G.; Jouvin, K.; Martin-Mingot, A.; Evano, G.; Marrot, J.; Thibaudeau, S. Chem. Commun. 2012, 48, 5196. (n) Ung, G.; Mendoza-Espinosa, D.; Bertrand, G. Chem. Commun. 2012, 48, 7088. (o) Gati, W.; Rammah, M. M.; Rammah, M. B.; Couty, F.; Evano, G. J. Am. Chem. Soc. 2012, 134, 9078. (p) Karad, S. N.; Bhunia, S.; Liu, R.-S. Angew. Chem. Int. Ed. 2012, 51, 8722 . (q) DeKorver, K. A.; Hsung, R. P.; Song, W.-Z.; Wang, X. N.; Walton, M. C. Org. Lett. 2012, 14, 3214. (r) Minko, Y.; Pasco, M.; Lercher, L.; Botoshansky, M.; Marek, I. Nature (London, U. K.) 2012, 490, 522.
(7) For the use of ynamides in natural product synthesis, see: (a) Zhang, Y.; Hsung, R. P.; Zhang, X.; Huang, J.; Slafer, B. W.; Davis, A. Org. Lett. 2005, 7, 1047. (b) Couty, S.; Liegault, B.; Meyer, C.; Cossy, J. Tetrahedron 2006, 62, 3882. (c) Alayrac, C.; Schollmeyer, D.; Witulski, B. Chem. Commun. 2009, 1464. (d) Gourdet, B.; Lam, H. W. Angew. Chem. Int. Ed. 2010, 49, 8733. (e) Mak, X. Y.; Crombie, A. L.; Danheiser, R. L. J. Org. Chem. 2011, 76, 1852.

(f) Dassonneville, B.; Witulski, B.; Detert, H. Eur. J. Org. Chem. 2011, 2836. (g) Nissen, F.; Detert, H. Eur. J. Org. Chem. 2011, 2845. (h) Saito, N.; Ichimaru, T.; Sato, Y. Org. Lett. 2012, 14, 1914.

(8) Wei, L.-L.; Mulder, J. A.; Xiong, H.; Zificsak, C. A.; Douglas, C. J.; Hsung, R. P. Tetrahedron 2001, 57, 459.

(9) Katritzky, A. R.; Zhang, S.; Fang, Y. Org. Lett. 2000, 2, 3789 .

(10) (a) Brückner, D. Synlett 2000, 1402. (b) Rodríguez, D.; Castedo, L.; Saá, C. Synlett 2004, 783. (c) Brückner, D. Tetrahedron 2006, 62, 3809. (d) Katritsky, A. R.; Singh, S. K.; Jiang, R. Tetrahedron 2006, 62, 3794. (e) MartínezEsperón, M. F.; Rodríguez, D.; Castedo, L.; Saá, C. Tetrahedron 2006, 62, 3843. (f) Rodríguez, D.; MartínezEsperón, M. F.; Castedo, L.; Saá, C. Synlett 2007, 1963.

(11) Couty, S.; Barbazanges, M.; Meyer, C.; Cossy, J. Synlett 2005, 905 .

(12) Nadipuram, A. K.; David, W. M.; Kumar, D.; Kerwin, S. M. Org. Lett. 2002, 4, 4543.

(13) Huang, J.; Xiong, H.; Hsung, R. P.; Rameshkumar, C.; Mulder, J. A.; Grebe, T. P. Org. Lett. 2002, 4, 2417.

(14) (a) Tracey, M. R.; Zhang, Y.; Frederick, M. O.; Mulder, J. A.; Hsung, R. P. Org. Lett. 2004, 6, 2209. (b) MartínezEsperón, M. F.; Rodríguez, D.; Castedo, L.; Saá, C. Tetrahedron 2008, 64, 3674. (c) Wakamatsu, H.; Takeshita, M. Synlett 2010, 2322. (d) Witulski, B.; Schweikert, T.; Schollmeyer, D.; Nemkovich, N. A. Chem. Commun. 2010, 46, 2953.

(15) For a review on the chemistry of hypervalent alkynyliodonium salts, see: (a) Zhdankin, V. V.; Stang, P. J. Tetrahedron 1998, 54, 10927. For a review on electrophilic alkynylation, see: (b) Brand, J. P.; Waser, J. Chem. Soc. Rev. 2012, 41, 4165.

(16) Murch, P.; Williamson, B. L.; Stang, P. J. Synthesis 1994, 1255.

(17) Representative examples with metalated sulfonamides: (a) Witulski, B.; Stengel, T. Angew. Chem. Int. Ed. 1998, 37, 489. (b) Witulski, B.; Stengel, T. Angew. Chem. Int. Ed. 1999, 38, 2426. (c) Witulski, B.; Gössmann, M. Chem. Commun. 1999, 1879. (d) Rainier, J. D.; Imbriglio, J. E. Org. Lett. 1999, 1, 2037. (e) Rainier, J. D.; Imbriglio, J. E. J. Org. Chem. 2000, 65, 7272. (f) Witulski, B.; Gössmann, M. Synlett 2000, 1793. (g) Witulski, B.; Stengel, T.; FernandezHernandez, J. M. Chem. Commun. 2000, 1965. (h) Witulski, B.; Alayrac, C. Angew. Chem. Int. Ed. 2002, 41, 3281. (i) Witulski, B.; Lumtscher, J.; Bersträber, U. Synlett 2003, 708. (j) Klein, M.; König, B. Tetrahedron 2004, 60, 1087. Also see refs. 6k and 14d. Representative examples with metalated amides: (k) Tanaka, K.; Takeishi, K. Synthesis 2007, 2920. Also see refs. 7b and 15a. Representative example with metalated carbamates: (1) Hashmi, A. S. K.; Salathe, R.; Frey, W. Synlett 2007, 1763. Representative examples of intramolecular versions: (m) Feldmann, K. S.; Bruendl, M. M.; Schildknegt, K. J. Org. Chem. 1995, 60, 7722. (n) Feldmann, K. S.; Bruendl, M. M.; Schildknegt, K.; Bohnstedt, A. C. J. Org. Chem. 1996, 61, 5440. (o) Schildknegt, K.; Bohnstedt, A. C.; Feldmann, K. S.; Sambandam, A. J. Am. Chem. Soc. 1995, 117, 7544. 
(18) Representative examples with metalated N-heterocycles: (a) Kitamura, T.; Tashi, N.; Tsuda, K.; Fujiwara, Y. Tetrahedron Lett. 1998, 39, 3787. (b) Kitamura, T.; Tashi, N.; Tsuda, K.; Chen, H.; Fujiwara, Y. Heterocycles 2000 , 52, 303. (c) Kerwin, S. M.; Nadipuram, A. Synlett 2004, 1404. (d) Denonne, F.; Seiler, P.; Diederich, F. Helv. Chim. Acta 2003, 86, 3096. (e) Nadipuram, A. K.; Kerwin, S. M. Tetrahedron Lett. 2006, 47, 353.

(19) For representative examples, see refs $14 \mathrm{~b}$ and $17 \mathrm{c}$.

(20) Souto, J. A.; Becker, P.; Iglesias, A.; Muñiz, K. J. Am. Chem. Soc. 2012, 134, 15505.

(21) For reviews on copper catalysis, see: (a) Monnier, F.; Taillefer, M. Angew. Chem. Int. Ed. 2009, 48, 6954. (b) Evano, G.; Blanchard, N.; Toumi, M. Chem. Rev. 2008, 108,3054

(22) Surry, D. S.; Buchwald, S. L. Chem. Sci. 2010, 1, 13.

(23) Frederick, M. O.; Mulder, J. A.; Tracey, M. R.; Hsung, R. P.; Huang, J.; Kurtz, K. C. M.; Shen, L.; Douglas, C. J. J. Am. Chem. Soc. 2003, 125, 2368.

(24) (a) Dunetz, J. R.; Danheiser, R. L. Org. Lett. 2003, 5, 4011. (b) Kohnen, A. L.; Dunetz, J. R.; Danheiser, R. L. Org. Synth. 2007, 84, 88 .

(25) (a) Zhang, Y.; Hsung, R. P.; Tracey, M. R.; Kurtz, K. C. M.; Vera, E. L. Org. Lett. 2004, 6, 1151. (b) Zhang, X.; Zhang, Y.; Huang, J.; Hsung, R. P.; Kurtz, K. C. M.; Oppenheimer, J.; Petersen, M. E.; Sagamanova, I. K.; Shen, L.; Tracey, M. R. J. Org. Chem. 2006, 71, 4170. (c) Sagamanova, I. K.; Kurtz, K. C. M.; Hsung, R. P. Org. Synth. 2007, 84, 359.

(26) Istrate, F. M.; Buzas, A. K.; Jurberg, I. D.; Odabachian, Y.; Gagosz, F. Org. Lett. 2008, 10, 925.

(27) DeKorver, K. A.; Walton, M. C.; North, T. D.; Hsung, R. P. Org. Lett. 2011, 13, 4862.

(28) Chen, Z.; Zeng, W.; Jiang, H.; Liu, L. Org. Lett. 2012, 14, 5385.

(29) (a) Laroche, C.; Li, J.; Freyer, M. W.; Kerwin, S. M. J. Org. Chem. 2008, 73, 6462. (b) Burley, G. A.; Davies, D. L.; Griffith, G. A.; Lee, M.; Singh, K. J. Org. Chem. 2010, 75, 980. (c) Das, B.; Reddy, G. C.; Balasubramanyam, P.; Salvanna, N. Synthesis 2011, 816.

(30) Dooleweerdt, K.; Birkedal, H.; Ruhland, T.; Skrydstrup, T. J. Org. Chem. 2008, 73, 9447.

(31) Yao, B.; Liang, Z.; Niu, T.; Zhang, Y. J. Org. Chem. 2009, 74, 4630.

(32) Buchwald, S. L.; Bolm, C. Angew. Chem. Int. Ed. 2009, 48, 5586.

(33) For reviews on the use of gem-dibromoalkenes in transitionmetal-mediated cross-coupling reactions, see: (a) Legrand, F.; Jouvin, K.; Evano, G. Isr. J. Chem. 2010, 50, 588. (b) Chelucci, G. Chem. Rev. 2012, 112, 1344.

(34) (a) Ramirez, F.; Desal, N. B.; McKelvie, N. J. Am. Chem. Soc. 1962, 84, 1745. (b) Fang, Y.-Q.; Lifchits, O.; Lautens, M. Synlett 2008, 413. (c) Bryan, C.; Aurregi, V.; Lautens, M. Org. Synth. 2009, 86, 36.

(35) (a) Coste, A.; Karthikeyan, G.; Couty, F.; Evano, G. Angew. Chem. Int. Ed. 2009, 48, 4381. (b) Coste, A.; Couty, F.; Evano, G. Org. Synth. 2010, 87, 231. (c) Jouvin, K.; Coste,
A.; Bayle, A.; Legrand, F.; Karthikeyan, G.; Tadiparthi, K.; Evano, G. Organometallics 2012, 31, 7933.

(36) Coste, A.; Couty, F.; Evano, G. Synthesis 2010, 1500.

(37) Coste, A.; Couty, F.; Evano, G. Org. Lett. 2009, 11, 4454.

(38) Jouvin, K.; Evano, G. Chim. Oggi 2011, 29, 31.

(39) Wang, M.-G.; Wu, J.; Shang, Z.-C. Synlett 2012, 23, 589.

(40) Das, B.; Salvanna, N.; Reddy, G. C.; Balasubramanyam, P. Tetrahedron Lett. 2011, 52, 6497.

(41) Yang, Y.; Zhang, X.; Liang, Y. Tetrahedron Lett. 2012, 53, 6557.

(42) Sueda, T.; Oshima, A.; Teno, N. Org. Lett. 2011, 13, 3996.

(43) For reviews on catalytic oxidative cross-coupling reactions, see: (a) Wendlandt, A. E.; Suess, A. M.; Stahl, S. S. Angew. Chem. Int. Ed. 2011, 50, 11062. (b) Liu, C.; Zhang, H.; Shi, W.; Lei, A. Chem. Rev. 2011, 111, 1780.

(44) Peterson, L. I.; Britton, E. C. Tetrahedron Lett. 1968, 9, 5357.

(45) Balsamo, A.; Macchia, B.; Macchia, F.; Rossello, A.; Domiano, P. Tetrahedron Lett. 1985, 26, 4141.

(46) Hamada, T.; Ye, X.; Stahl, S. S. J. Am. Chem. Soc. 2008, 130,833

(47) Arai, T.; Kawasaki, N.; Kanoh, H. Synlett 2012, 23, 1549.

(48) Tong, X.; Ni, G.; Deng, X.; Xia, C. Synlett 2012, 23, 2497.

(49) Jin, X.; Yamaguchi, K.; Mizuno, N. Chem. Commun. 2012, 48,4974

(50) Laouiti, A.; Rammah, M. M.; Rammah, M. B.; Marrot, J.; Couty, F.; Evano, G. Org. Lett. 2012, 14, 6.

(51) For a review on the Chan-Lam-Evans cross-coupling, see: Qiao, J. X.; Lam, P. Y. S. Synthesis 2011, 829.

(52) (a) Alkynylboronic acids were mentioned later on in a single publication and could not be observed during the hydrolysis of the corresponding potassium phenylethynyltrifluoroborate where, in contrast to other aryl- or vinyltrifluoroborates, only the protodeborylated product (phenylacetylene) was observed. ${ }^{52 b}$ All other hits obtained from SciFinder or Reaxys searches correspond to errors in these databases (b) Lennox, A. J. J.; Lloyd-Jones, G. C. J. Am. Chem. Soc. 2012, 134, 7431 .

(53) For reviews on the chemistry of organotrifluoroborate salts, see: (a) Molander, G. A.; Figueroa, R. Aldrichimica Acta 2005, 38, 49. (b) Molander, G. A.; Ellis, N. Acc. Chem. Res. 2007, 40, 275. (c) Darses, S.; Genet, J.-P. Chem. Rev. 2008, $108,288$.

(54) Jouvin, K.; Couty, F.; Evano, G. Org. Lett. 2010, 12, 3272.

(55) Jia, W.; Jiao, N. Org. Lett. 2010, 12, 2000.

(56) For general references on the oxidation of organocopper reagents, see: (a) Surry, D. S.; Spring, D. A. Chem. Soc. Rev. 2006, 35, 218. (b) Aves, S. J.; Spring, D. R. The Chemistry of Organocopper Compounds, In The Chemistry of Functional Groups; Vol. 24; Rappoport, Z.; Marek, I., Eds.; John Wiley \& Sons Ltd: Chichester, 2009, 585.

(57) Jouvin, K.; Heimburger, J.; Evano, G. Chem. Sci. 2012, 3, 756.

(58) Laouiti, A.; Jouvin, K.; Rammah, M. M.; Rammah, M. B.; Evano, G. Synthesis 2012, 44, 1491.

(59) Beveridge, R. E.; Batey, R. A. Org. Lett. 2012, 14, 540. 